\title{
Experiencias con Multimedios en Programas a Distancia
}

\author{
(Experiences with Multimedia in Distance Programs)
}

\author{
LUISA A. NOA SILVERIO \\ Facultad de Educación a Distancia. \\ Universidad de La Habana \\ (Cuba.)
}

RESUMEN: La utilización de las Nuevas Tecnologías en los programas a distancia plantea una serie de interrogaciones, especialmente en relación con la adecuación de estas tecnologías a las características socioculturales en que se desarrollan estos programas educacionales. La potencialidad de esta tecnología para la enseñanza y el aprendizaje exige que se realicen en nuestro medio, estudios que permitan su gradual incorporación y aprovechamiento.

El presente trabajo describe las experiencias en la elaboración de una aplicación multimedia y su utilización, de forma experimental, por los estudiantes de la carrera de Historia en la modalidad a distancia. En el trabajo se hace énfasis en el diseño instruccional para multimedia y la necesidad de que la aplicación multimedia creada ofrezca facilidades que permitan satisfacer determinados hábitos de estudio, se brindan, además, los resultados más importantes obtenidos.

\section{Multimedia - Hipertexto - Diseño de hipertexto - Palabra caliente - Interactividad}

ABSTRACT: The application of the New Technologies into distance education programs set a lot of questions, especially in relation with the characteristics of the social and cultural environment in which these programs are developed. The possibilities of the New Technology for teaching and learning demand beginning of researches that would help us to incorporate this New Technology in the future.

The paper presents our experiences in the confection of multimedia application and its use, in an experimental form for our students of the specialty of History in a multimedia instructional design. Finally, in the paper 1 discus the main results obtained and describe our future projects with multimedia.

\section{Multimedia - Hypertext - Hypertext Design - Hotword - Interactivity.}

\section{INTRODUCCIÓN}

Desde hace algún tiempo, más exactamente, a finales de la década pasada y principios de ésta, se ha generalizado un enfoque mediático de las etapas de desarrollo de la educación a distancia (Nipper, 1989). De acuerdo con esta visión, actualmente la educación a distancia se encuentra en una etapa de desarrollo denominada de cuarta generación, que se caracteriza por la incorporación de la telemática y la informática. Hoy en día, se imparten numerosos cursos a través de la Red de Redes: Internet —a distancia, por supuesto — que llevan a cabo programas terminales en Universidades Virtuales.

Lo expuesto no implica que todos los programas e instituciones en educación a distancia evolucionen actualmente hacia la cuarta generación. En la actualidad coexisten y coexistirán por algún tiempo, todas las formas posibles (e incluso los cursos por correspondencia), en dependencia de los objetivos, clientela, recursos y características del área geográfica donde se difunden esos programas. Lo más importante de este enfoque mediático es que subraya la tendencia de la educación a distancia a sumarse o (más bien a ser arrastrada) hacia los grandes cambios y retos del presente.

Las nuevas tecnologías de información brindan la posibilidad de aumentar el espectro de interrelaciones educativas entre profesores-estudiantes, tutores-estudiantes, expertos-estudiante y estudiante-estudiante. Para las instituciones a distancia que ya tienen algunos años de creadas, surge el reto de incorporar inteligentemente las nuevas tecnologías de información y comunicación que hacen posible establecer nuevos formas de aprendizaje. 
En este sentido cabe preguntarse: ¿Cómo podemos incorporar las nuevas tecnologías para generar ambientes efectivos de colaboración que permitan la individualización del aprendizaje y que propicien dichas interacciones? ¿Cuáles son los cambios estructurales que deben producirse? ¿Cuáles las inversiones en recursos humanos y equipamiento que debemos realizar? Como consecuencia lógica se deduce que debemos generar experiencias que nos ayuden a comprender estas tendencias y nos capaciten para decidir hacia donde debemos invertir nuestros escasos recursos. Estas experiencias a su vez generarán la cultura necesaria para retroalimentar los cambios. Como dice el poeta: «se hace camino al andar) $>$.

Entre estas nuevas tecnologías de información se encuentran los multimedios, que brindan la posibilidad de:

- entrelazar textos con recursos audiovisuales,

- posibilitar la selección de la información requerida,

- responder a las necesidades de cada estudiante,

- $\quad$ posibilitar una mayor flexibilidad en relación con los estilos de aprendizajes.

Flexibilidad cognitiva (Spiro, 1990), individualización, interactividad y auto- control del aprendizaje son términos que caracterizan la utilización de los multimedios en educación. Ya es una realidad el proceso de fusión entre multimedios y las redes de comunicación, la interactividad de los multimedios se funde ahora con la interactividad entre los actores del proceso educativo.

La experiencia, que a continuación expondremos, está enmarcada, precisamente, en la utilización de los multimedios aplicados a los programas a distancia en la Facultad de Educación a Distancia de la Universidad de La Habana.

\section{OBJETIVOS CENTRALES Y ETAPAS DE LA EXPERIENCIA}

El interés principal de esta experiencia con multimedios se centraba y se centra en poder determinar las acciones que deben emprenderse para emplear, asimilar o utilizar esta tecnología en nuestros programas, sobre esta dirección se situaron las siguientes interrogaciones:

- ¿ ¿Cuáles son las condiciones de aplicación de productos multimedia en la educación a distancia?

- ¿ ¿Qué ventajas y desventajas presentan su aplicación al modelo de educación a distancia que sustenta nuestros programas?

- ¿ ¿Cómo evaluar dichos productos para que sean seleccionados o no?

Las que se sintetizaron en los siguientes objetivos:

- Estudiar la elaboración y aplicación de productos multimedia, su efectividad y el entorno cognoscitivo necesario que deberá generarse para la utilización de dicho medio.

- Extraer conclusiones y recomendaciones para su utilización.

Para ello se propuso un proyecto que tenía como primer momento el diseño y elaboración de una aplicación multimedia.

El proyecto para la elaboración y aplicación de un producto multimedia para la asignatura Historia Social de la Literatura y el Arte II se presentó a finales del curso 1994-95 e incluía los temas referidos al análisis de las obras de los grandes exponentes del arte renacentista. Las etapas que se cumplieron para lograr el objetivo de diseñar y elaborar una aplicación multimedia, fueron las siguientes:

- $\quad$ preparación del personal que trabajaría con el software para su creación: sistema de autor,

- estudio bibliográfico en tres direcciones: diseño instruccional con multimedios, utilización de los multimedios en la educación superior, y lo referente al Arte Renacentista,

- diseño general de la aplicación —uso de recursos de navegación, glosario de términos, uso de iconos, efectos sonoros, etc.—y desarrollo del guión,

- $\quad$ selección de las imágenes y su procesamiento, 
- selección de los efectos especiales que se utilizarían en la computadora para mostrar la composición y estructura de las obras,

- diseño y aplicación de cuestionarios y entrevistas a expertos y a usuarios como elementos de su evaluación formativa.

Este proyecto estaba a cargo del Grupo de Tecnología Educativa de la Facultad. En sus inicios este grupo incluía 4 estudiantes de la Facultad de Cibernética Matemática, una profesora del Departamento de Historia del Arte de la Facultad de Artes y Letras, con experiencia en impartir esta materia y la autora de este artículo como directora del proyecto. Contamos también con la ayuda de los metodólogos de la Facultad. Al final del primer año se incorporó un graduado de la Facultad de Cibernética Matemática y terminaron su labor los 4 estudiantes.

Sin entrar en una evaluación de las etapas que recorrimos, es necesario señalar que el trabajo de elaboración del guión y de su implementación en el sistema de autor seleccionado se realizó en partes bien definidas. Es decir, una vez que se decidió el esquema general que tendría la aplicación, se procedió a elaborar por partes el guión, ajustándonos al orden cronológico de las obras. No se esperó tenerlo todo diseñado, sino que muchas de las tareas de elaboración del guión, selección de imágenes u otros recursos, implementación, etc. se hacían de forma simultánea. A veces, una imagen era sustituida varias veces con el objetivo de obtener una mayor calidad. El diseño de una unidad o de determinados efectos también se modificaron varias veces.

Cuando comenzamos, el grupo no tenía experiencia. La mayor preocupación era utilizar al máximo los recursos disponibles para presentar los conceptos de la forma más sencilla y natural a los estudiantes. Tratamos de seguir las experiencias que se exponían en la literatura, pero la vida es más rica que cualquier esquema y muchos de los pasos emprendidos se hicieron de forma intuitiva, porque se desprendían de lo que ya habíamos andado o porque en nuestras circunstancias no nos quedaba otra alternativa.

Los recursos a nuestra disposición fueron escasos y tuvimos que recurrir a ayudas externas para obtener determinados servicios y acceso a equipos no existentes en nuestra Facultad. Por último, la aplicación elaborada, que recibió el nombre de «Grandes Maestros del Renacimiento», fue llevada a formato CD-ROM en octubre de 1997. Esta aplicación ha servido para realizar experiencias en un curso presencial en la Facultad de Artes y Letras y en tres grupos de estudiantes - dos cursos consecutivosen la Facultad de Educación a Distancia. En la actualidad este material multimedia se utiliza en un taller semi-presencial sobre «Multimedia e Historia〉' que se imparte a historiadores graduados en nuestros programas a distancia y se ha utilizado en cursos de Postgrado Internacional para su evaluación y como muestra de la utilización de técnicas de diseño y elaboración de software educativos. Sobre la base de estas experiencias se han elaborado otros posibles proyectos en dos asignaturas de la Carrera de Derecho y de Historia.

No deseamos esquivar la pregunta que seguramente se hace el lector: ¿Por qué elaboramos nosotros mismos la aplicación y no adquirimos un producto comercial?, por ejemplo: ¿una enciclopedia multimedia, que nos proporcionara, al menos, parte de las obras tratadas? Las razones fueron las siguientes:

a) La dificultad para encontrar un producto comercial que se ajuste a los contenidos exigidos por nuestros programas.

b) La necesidad que el software cumpla con determinados requisitos y estrategias de aprendizaje que el material de instrucción debe cumplir para que éstos sean verdaderamente efectivos y aceptados por los estudiantes de educación a distancia.

Con los productos multimedia pasa algo similar que con los videos educacionales. Por razones parecidas a las expuestas, además de agregar lo costoso de las escenas, se hace necesario buscar la forma de reutilizar estos recursos mediante una recomposición que produzca nuevos videos y que se ajusten a objetivos específicos. Esta necesidad ha impulsado las investigaciones y los esfuerzos para construir bibliotecas digitalizadas de vídeo, donde cada vídeo tendría una referencia de sus componentes, lo que facilitaría su localización. Los esfuerzos para producir dichas referencias para los componentes de vídeo con el propósito de que las secciones deseadas sean recuperadas y reutilizadas, han sido, hasta el momento, muy poco exitosos. (Rada, 1995). Lo ideal para nosotros hubiera sido reutilizar los recursos existentes para multimedios interactivos. 
En nuestro caso, la aplicación cubriría, además, la falta de libros especializados y reproducciones gráficas en las bibliotecas que frecuentan nuestros estudiantes. La limitación en estos recursos no es un problema que atenta directamente en la aprobación de la asignatura Historia Social de la Literatura y del Arte II, pero sin duda, repercute sobre la calidad del aprendizaje.

\section{LAS TÉCNICAS DE HIPERTEXTO Y LOS RECURSOS EN LA APLICACIÓN GRANDES MAESTROS DEL RENACIMIENTO.}

Propiedades de los hipertextos y la cognición.

Antes de exponer las características del diseño hipertextual en la aplicación «Grandes Maestros del Renacimiento», debemos detenernos un poco en aquellas tesis sobre las propiedades de los hipertextos y en los posibles recursos para el aprendizajes que pueden ser ofrecidas para dar control al estudiante y permitir la interactivad. Expondremos sólo aquellas tesis que más influyeron en el trabajo.

Las siguientes consideraciones (Spiro, 1990) estuvieron presentes, como fondo teórico:

a) Definir los propósitos del aprendizaje, por los cuales este ambiente mstruccional, no familiar, debe ser utilizado (no todo aprendizaje lo requiere).

b) Posibilitar el aprendizaje no lineal — los sistemas de hipertexto serían fáciles de utilizar y soportarían grandes logros educacionales si fueran sistemáticamente diseñados en concordancia con una teoría de cómo la información será procesada, representada mentalmente y posteriormente usada.

Otras estrategias que fueron consideradas son las expuestas por Gagné (Marshal, 1996) y que en la literatura que trata estos problemas, ocupan un lugar importante:

a) Conocer las características de los que aprenden

b) Determinar los objetivos instruccionales.

c) Selección de las estrategias cognitivas que permitan:

- Capturar la atención del aprendiz

- Provocar el recuerdo de conocimientos que el aprendiz tiene en su memoria de largo plazo y que serán necesarios para la construcción del nuevo conocimiento.

- Suministrar guías de aprendizaje que faciliten la estructuración del aprendizaje.

d) Evaluar los resultados generales vinculados con los objetivos y estrategias utilizadas.

También hemos considerado otros aspectos no mencionados arriba y que están íntimamente vinculados con otras concepciones que individualizan el aprendizaje: la existencia de diferentes estilos cognitivos. Según Entwistle (1988) se han identificado como mínimo diecinueve maneras distintas de describir el estilo cognitivo pero todas consisten en presentar dos polos:

convergente-divergente

reflexivo-impulsivo

articulado-global

Por ello hemos tratado que en el producto multimedia elaborado se reflejen estas exigencias y que en él se pueda dosificar en forma conveniente la sugerencia de un orden lógico, combinado con una cierta libertad de navegación para la selección de los tópicos. En educación a distancia estas consideraciones se sitúan en un plano preferencial porque en estas condiciones se promueve y se privilegia que el estudiante sea su propio gestor y censor del aprendizaje.

Características utilizadas de los hipertextos y las estrategias de aprendizajes.

La aplicación «Grandes Maestros del Renacimiento», da control al estudiante sobre:

- $\quad$ navegación (selección de temáticas y orden de las mismas), moverse entre páginas de una misma unidad de información, 
- $\quad$ acceso a un glosario de términos alfabéticamente organizado,

- utilización o acceso a mayor información mediante las palabras activas («hotword»), que incluyen, además en algunos casos, efectos especiales,

- $\quad$ visualización de detalles de las obras,

- impresión de los contenidos de las ventanas del glosario de términos y de las palabras activas,

- activar o desactivar la música de fondo, que en este caso comprende música de los siglos XV y XVI,

- $\quad$ activar o desactivar la locución del programa,

- consultar al tutor mediante una ventana que puede abrir a discreción y donde puede escribir sus mensajes, Consultar una especie de pizarra (ventana), cori las. EeSJ?UsÑs. . las. 9JQ\%l»iIas toiJd iQ 11 S,

- $\quad$ realizar ejercitaciones de autoevaluación y dejar sus respuestas para ser evaluadas por el tutor.

Nexos entre los nodos o unidades de información.

El siguiente esquema ( Ver Fig. No. 1) presenta las unidades de información como nodos de hipertexto, las facilidades de navegación, así como los nexos jerárquicos existentes en el programa.

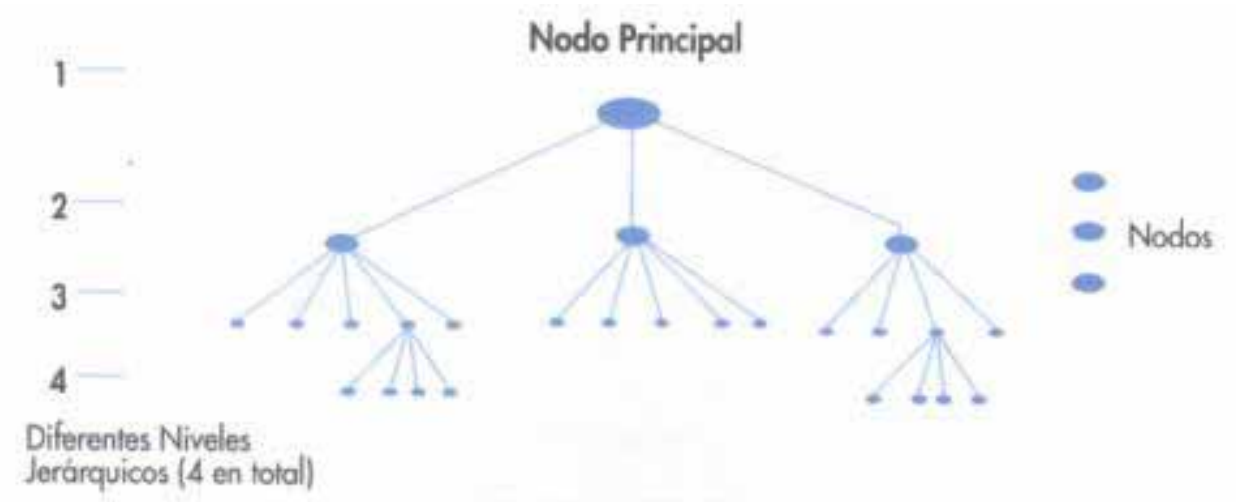

Como puede verse, los nodos de información se conectan entre sí mediante una lógica jerárquica que sigue el patrón de lo general a lo particular, lo que se combina con un orden temporal de las obras. No obstante, se presenta, como opción, una forma más sencilla de acceder la información a través del nodo principal, desde donde se puede alcanzar cualquier unidad básica de información: las obras de los representantes del Renacimiento. Esto último se concibió para dar al estudiante una visión de conjunto del contenido del programa desde el nodo principal. Para lograr este objetivo se utiliza la metáfora: "índice de un libro", es decir presentar esta primera pantalla como si fuera el índice de un libro de texto impreso. Dicho índice está compuesto de palabras activas que sirven de nexos para desplazarse a los nodos de información. Con una sola mirada basta para tener la visión de conjunto del contenido de la aplicación. (Ver Fig. No. 2). 


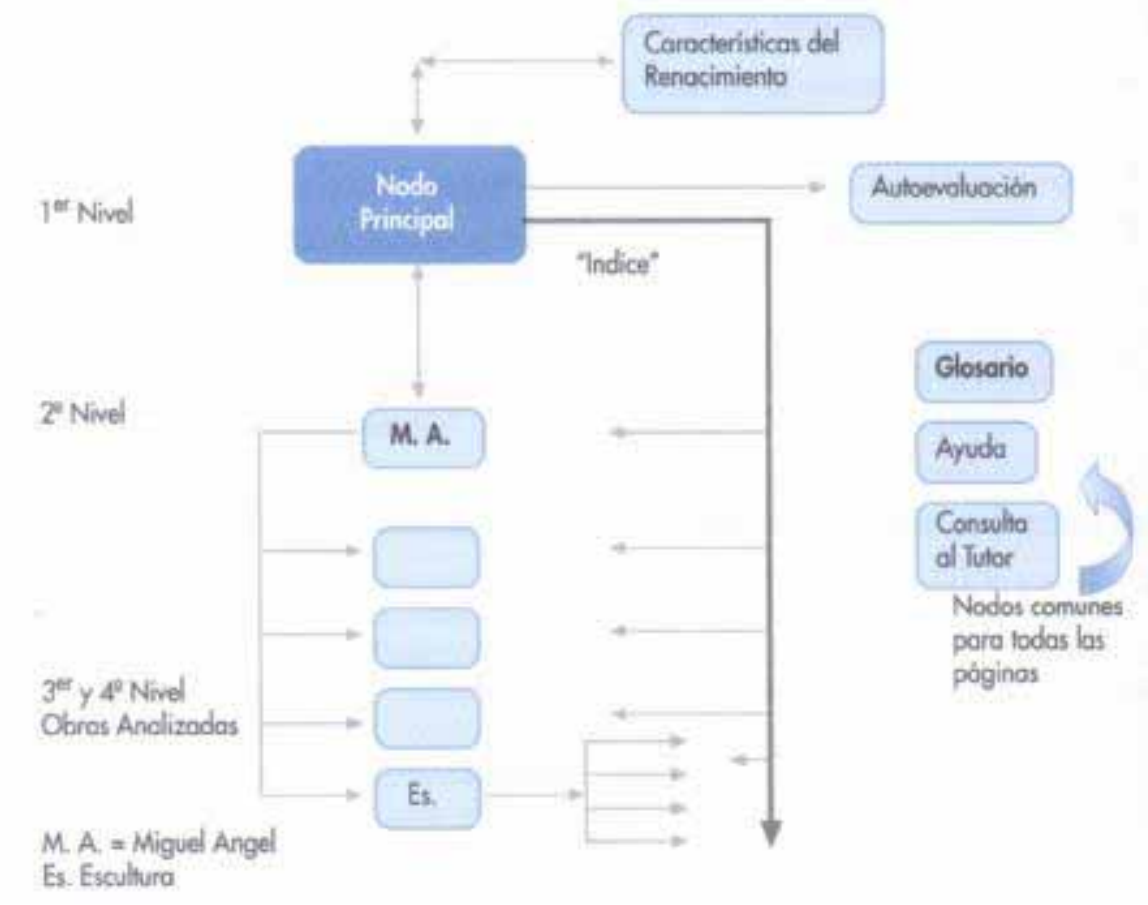

Figura 2. Esquema parcial del Hipertexto. Las obras se pueden acceder directamente desde el Nodo principal sin pasar por los niveles intermedios. Se presenta sólo el esquema para las obras de Miguel Angel

La intención de este índice "interactivo” es evitar la aparición de cierto sentimiento de frustración por pérdida de la orientación, algo frecuente al trabajar con hipertextos y desplazarse en la maraña de nodos o de bifurcaciones.

La estrategia de la navegación entre pantallas consecutivas se permite sólo cuando el nodo de información requiere más de una pantalla para ser expuesto, de lo contrario el «lector de hipertexto» deberá, para cambiar de tema (nuevo nodo de información), ir al Menú Principal o al Menú intermedio. La navegación en esta aplicación tiene estas reglas, las que son captadas fácilmente.

Facilidades generales que aparecen en todas las pantallas.

En el diseño de la aplicación, la parte inferior de las pantallas que se muestran al estudiante, se encuentran varios botones de funciones generales que acompañan a cada una de las pantallas. Cuando se coloca el puntero del «ratón» sobre uno de estos iconos, aparecerá, en pequeño letrero con la función que realiza, al estilo de las aplicaciones que corren sobre Windows'95 o sus versiones superiores.

Estos iconos son: Salida (fin de la ejecución), Ayuda, Acceso al glosario de términos, Regresar al menú principal o esquema general, Escribir Notas al profesor y Leer las respuestas del profesor, Activar o Desactivar la música de fondo o la voz de la locutora (Ver Fig. No. 3). También aparecen dos flechas que indican el sentido de la navegación entre páginas en la parte extrema derecha e inferior de la pantalla para los nodos que detallan las obras.

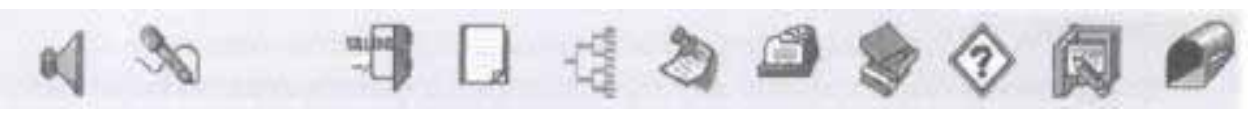

Figura 3. Los dos primeros iconos (de izquierda a derecha) son los de Música y Locución. Le sigue la Salida o finalizar la sesión, las Ejercitaciones de autoevaluación, el Esquema General, los Objetivos, la Bibliografía, el Glosario y la Ayuda. Los dos últimos son los de la comunicación con el tutor.

El programa guarda la siguiente información sobre el usuario: nombre del estudiante, unidades básicas de información que ha visitado y el tiempo que ha empleado en ello, las preguntas al tutor, si se han formulado, y las respuestas del tutor a sus estudiantes. De esta forma se logra un patrón de la sesión de 
trabajo que informa sobre la labor desarrollada por el estudiante para los efectos de retroalimentación del sistema y para la investigación.

El producto multimedia elaborado se ha utilizado en los cursos 1996-97 y 1997-98, 1998-99 por estudiantes de la carrera de Letras de la Facultad de Artes y Letras (enseñanza presencial) y por estudiantes de la Facultad de Enseñanza Dirigida (educación a distancia). Se solicitó a los estudiantes su colaboración en la investigación. La investigación puede calificarse de exploratoria y cualitativa. En todos los casos se aplicaron cuestionarios antes y después, se utilizó el método de observación, se realizaron entrevistas y se le solicitó opiniones a expertos en la materia.

4. resultados obtenidos con los estudiantes a distancia

Asistieron a la experiencia un total 35 estudiantes hasta la fecha de octubre de 1998. Los estudiantes participaron de forma voluntaria, es decir eligieron voluntariamente estudiar con la aplicación multimedia, no fueron seleccionados a través de muestreo. Esta forma de utilizar el medio ha sido tradicional en nuestra Facultad: el estudiante decide si va utilizar el medio o no, y cuando lo hará.

Las siguientes tablas muestran las características generales del grupo de estudiantes de la carrera de Historia que asistió a la experiencia.

\begin{tabular}{|ccc|}
\hline Sexo: & Cont. & $\%$ \\
\hline Femenino & 12 & 34 \\
\hline Masculino & 23 & 66 \\
TOTAL & 35 & 100 \\
\hline
\end{tabular}

Tabla 1. Distribudón por sexo.

Como puede observarse el porcentaje más alto de los participantes es del sexo masculino.

Es interesante destacar que el $50 \%$ de los participantes eran trabajadores.

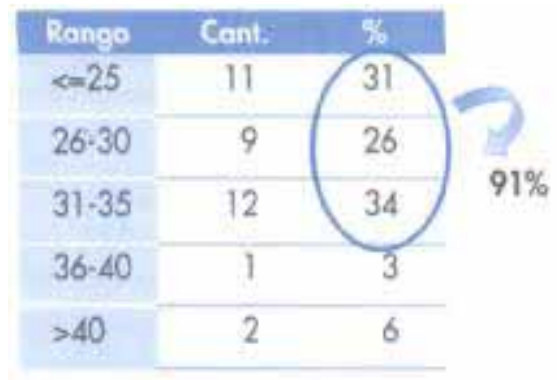

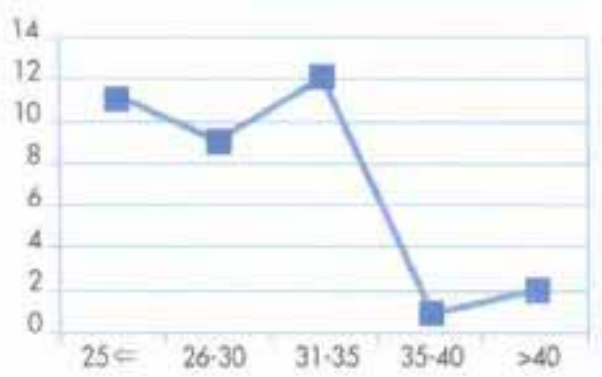

Tabla 2 y Figura 4. Distribudón por edades.

En la Tabla No. 2 y en la Fig. No. 4 se aprecia que los rangos de edades más significativos están comprendidos entre 25 y 35 años.

La Tabla No. 3 muestra que el número mayoritario de participantes viven en municipios cercanos a las instalaciones de la Facultad donde se realizó la experiencia.

\begin{tabular}{|c|c|c|}
\hline Proximidad & Contidad & $\%$ \\
\hline Muy próximos & 13 & \\
\hline Relativamente próximos & 11 & \\
\hline Alejodos & 7 & \\
\hline Muy Alejodos & 4 & 12 \\
\hline Total & 35 & 100 \\
\hline
\end{tabular}


Tabla 3. Distribución de los participantes por la proximidad de los municipios de residencia a la Sede Central.

El 68\% de los participantes residían en municipios "Muy próximos” o "Relativamente próximos” a la Facultad, donde se realizó la experiencia.

Sobre sus experiencias con la computadora.

El 63\% de los participantes califican como "Regular” su familiaridad con las computadoras, el resto opina que está “Poco” familiarizado. El 60\% había recibido algún curso en ambiente DOS. El 60\% refiere tener acceso a computadoras. Ningún caso reporta no saber nada sobre computadoras.

De los intercambios de opiniones con los participantes, 21\% refiere que muchos estudiantes no han venido a participar en la experiencia por tener un conocimiento elemental o casi ninguno sobre la utilización de las computadoras, lo que genera temor al medio.

Estas características del grupo que participó en la experiencia propició la rápida adquisición de habilidades para trabajar con el “ratón” y su ubicación en los recursos de navegación.

Formas de estudio.

El 93\% de los participantes estudia de forma individual y el 80\% declara que toman notas cuando estudian. De éstos un 50 \% hace cuadros sinópticos y resúmenes.

Existe por tanto una reelaboración del material impreso por parte del estudiante. Este comportamiento del estudiante frente al material escrito, así como el estudio preferentemente individual, es típico del estudiante a distancia en nuestro medio. Los estudiantes utilizan estas formas de estudio para organizar, reestructurar los contenidos y fijar su conocimiento.

Ahora bien: ¿Cómo se reflejan estos hábitos cuando se estudia mediante multimedia? Cuando utilizamos la aplicación en el curso regular de la carrera de Letras —estudiantes de la modalidad presencial-, éstos acudían a la computadora con sus libretas de notas e incluso se distribuyeron los temas con el objetivo de intercambiar las notas tomadas a partir de los textos presentados en la pantalla. En el caso de los estudiantes a distancia, se les proporcionó la posibilidad de utilizar la capacidad instalada en la aplicación, de imprimir los textos de algunas palabras activas y el contenido de los conceptos que aparecen en el Glosario. Como promedio se imprimían dos o tres páginas por estudiante. En el cuestionario aplicado, éstos se quejaron de que los textos, que acompañan a las imágenes, no tenían la posibilidad de imprimirse.

En un inicio se pensó que sería una solución a este problema, darle a los estudiantes que acudían a trabajar con la aplicación multimedia, algún material escrito a manera de resumen y que no tuvieran que preocuparse en tomar notas. De esta forma, la atención se centraría en estudiar los textos en pantalla y realizar una lectura más profunda de las imágenes. Después de analizar e intercambiar con algunos estudiantes, se consideró que — sin rechazar la posibilidad de imprimir algún material escrito en un futuro - lo mejor sería dotar a la aplicación de facilidades para que el estudiante eligiera los textos que considere relevantes. En realidad, editar una especie de guía uniforma mucho las porciones de información y por el contrario, ofrecer esta otra posibilidad daría un mayor control del aprendizaje al estudiante, haría del acto de utilizar la aplicación una verdadera herramienta de estudio.

Dar control a los estudiantes en la elección de textos permitirá que el aprendizaje por computadoras se convierta en algo más natural, que se ajuste más a los métodos tradicionales utilizados en nuestro medio, donde el estudiante no cuenta con computadora personal en el hogar y tiene que plasmar los conceptos centrales y las ideas fundamentales en un medio o portador material como lo es una hoja de papel o su libreta de notas.

Consideramos que uno de los puntos críticos, al estudiar determinados contenidos presentados en multimedia, es ofrecer las facilidades necesarias al lector para reorganizar los contenidos, reelaborarlos e incluirlos en esquemas más o menos estructurados, facilitar la comunicación e intercambios de ideas, opiniones, dudas y la cooperación de los participantes en tareas comunes. Para lograr estos objetivos es posible utilizar varios métodos: la selección de textos y su impresión, la edición de los textos 
seleccionados mediante ventanas, la comunicación con otros estudiantes y tutores mediante mensajes electrónicos, sesiones de teleconferencias, etc.

Las investigaciones sobre la utilización de estos recursos aún no son tan definitorias como para ofrecer conclusiones que nos puedan orientar de una forma más precisa, además, no todos los entornos sociales de aplicación de estas tecnologías tienen las mismas características. En nuestro medio la computadora ya ocupa un lugar importante pero su difusión no alcanza tal nivel de desarrollo que pueda afectar las formas tradicionales de estudio. Este problema fue descrito de forma muy ilustrativa por un estudiante en una de las planillas:

« ... a la gente le va a resultar difícil acostumbrarse a estudiar así, hasta que el ordenador se vuelva algo más común.))

El análisis de la realidad socio-cultural donde desarrollamos nuestro trabajo debe estar presente a la hora de diseñar nuestras aplicaciones multimedia para que éstas cumplan los objetivos de aprendizaje trazados.

Otro foco de atención en la investigación fue indagar sobre el posible cansancio que pudiera aparecer al estar frente a la pantalla de la computadora por más de dos horas para estudiar los temas propuestos. El $100 \%$ de los estudiantes no manifestó preocupaciones al respecto. En una de las entrevistas realizadas a una estudiante se le preguntó que si le era difícil tomar notas de la pantalla, ya que tenía varias hojas escritas; su respuesta fue que no, que no sentía ninguna contrariedad en ello. Se le pidió que lo comparara con el libro de texto y el posible cansancio que genera la lectura en la pantalla; contestó que si hubiera tenido que estudiar el mismo tema con un libro lo más probable es que hubiese sentido sueño y no habría adelantado tanto.

En estas consideraciones está presente la potencialidad del medio, su novedad y su poder de generar altos grados de motivación que permite tensar las capacidades, generar niveles de atención espontánea, sin la necesidad de realizar esfuerzos adicionales y por el contrario, sentir placer por el acto de aprendizaje, que en definitiva es la mejor forma de estudiar. Debemos agregar también, que la naturaleza del tema tratado coopera a que el estudio mediante el uso de multimedios interactivos sea el más propicio.

Sobre la utilización de la aplicación.

El 93\% afirmó que la aplicación multimedia le ayudó a comprender las ideas centrales del tema y a fijar sus contenidos. El 43\% declara haber seguido el orden de estudio propuesto en el esquema general incluido en la primera pantalla. El 86\% considera de fácil comprensión los simbolismos e iconos utilizados. El 100\% no considera complicado el dominio sobre la computadora.

La aplicación guarda un registro por estudiante de los nodos visitados y el tiempo empleado en cada página o pantalla. De esta forma se obtuvo que el 73\% del tiempo empleado (35\% de los movimientos efectuados) como promedio, fue utilizado en leer, observar imágenes y consultar el glosario, el $27 \%$ restante del tiempo (67\% de los movimientos efectuados) se utilizó en navegar para ubicarse, entrenarse en el uso del menú u obtener una visión general del contenido de la aplicación.

Este índice se calculó globalmente y por participante y se define como la suma de los intervalos de tiempo mayor de un minuto que se ha utilizado para estudiar las pantallas, dividido entre el tiempo total empleado dentro de la aplicación.

Donde: $\mathrm{T}=$ tiempo total.

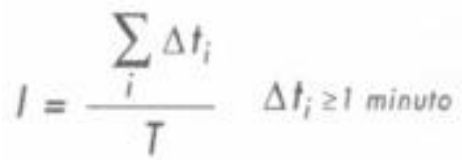

El tiempo promedio de lectura de texto y análisis de las imágenes es de dos minutos y medio por páginas. En un minuto el estudiante puede revisar los contenidos fundamentales aunque no realice la lectura de toda la información incluida en las palabras activas. Debido a estas consideraciones, se tomó un minuto como punto de partida para diferenciar los movimientos de localización de información y los de lectura y estudio. Puede parecer una medida arbitraria, pero los movimientos de ubicación, de reconocimiento y familiarización con las opciones que el programa brinda, son de unos 30 segundos o menos por pantalla, según las marcas registradas por la computadora para cada estudiante. 
Los resultados apuntan hacia lo siguiente: los estudiantes con una trayectoria en la Facultad de dos o tres cursos de estudio y con varias asignaturas aprobadas, se ubican más rápidamente en el ambiente gráfico y en las formas de navegación del programa.

Las gráficas de las trayectorias seguidas por cada uno de los participantes pueden reducirse a tres patrones generales de comportamiento: los que seguían el orden secuencial propuesto, los que seguían dicho orden pero volvían atrás, a ciertos nodos, para después continuar en el nodo donde se habían quedado y por último, los que consultaban el programa sólo en temas aislados de un interés específico. La Fig. No. 4 muestra un esquema de trabajo de un estudiante que siguió la trayectoria secuencial sugerida por el programa.

El estudio secuencial se presenta en dos de los patrones de comportamiento de los participantes frente al material de estudio, lo que sugiere que el estudiante asigna un voto de confianza a la secuencia implícita del material y consideramos importante, para los que se inician, ofrecerles una orientación sobre un cierto orden de estudio.

El nodo más visitado - todos los estudiantes con excepción de uno- fue el que contenía una explicación de las características generales del Renacimiento. Este nodo se accedía desde la página inicial (Ver Fig. No. 2).

Nuestros programas a distancia no contemplan la figura del tutor para consultas en materias especializadas. Los estudiantes reciben asesoría general —cómo organizar su tiempo, planificar los exámenes, consultar la bibliografía, etc.- una vez por semana. Desde el curso 1998-99 de forma experimental se han realizado asesorías especializadas en algunas de las asignaturas. Como se ha señalado, la aplicación multimedia daba posibilidades de dejar mensajes a un tutor, mediante una ventana donde el estudiante podía escribir sus dudas o consultas. Sólo dos estudiantes utilizaron la capacidad instalada en el sistema para comunicarse con el tutor. En realidad, el tutor es, en este caso, un ente anónimo, sin personalidad. Por otra parte, nuestros estudiantes, al no contar con consultas especializadas, no consideraron el mecanismo propuesto por el programa multimedia como algo vinculado a la realidad. El ambiente de trabajo creado en multimedia y la práctica académica estaban distanciados. Por esta razón hemos sugerido para el próximo curso unir ambos propósitos y vincular la utilización de la aplicación multimedia con consultas a tutores y expertos.

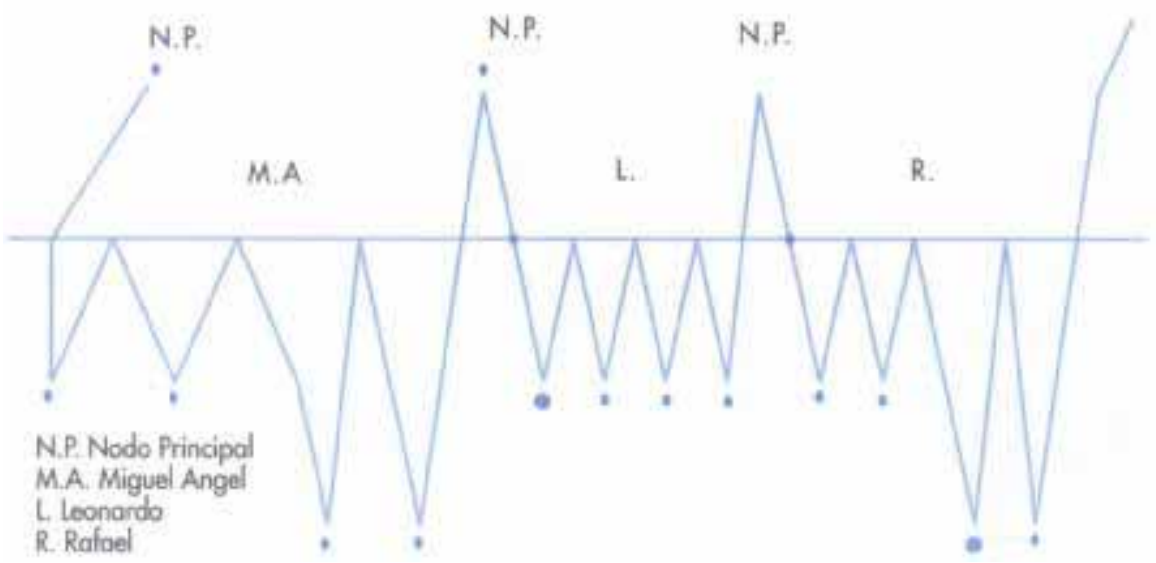

Figura 4. Esquema de la trayectoria de estudio seguida por un estudiante. El tamaño de las esferas indican el tiempo empleado en estudiar diferentes obras. Como puede apreciarse, la distribución del tiempo de lectura de los nodos es bastante uniforme. Utilizó los nodos intermedios que contienen el Menú para cada pintor en particular, lo que está indicado por la línea central. Visitó casi todos los nodos de información de forma secuencia. (Estudiante de 54 años de edad)

\section{EVALUACION DE LA APLICACIÓN MULTIMEDIA.}

Antes de utilizarse con los estudiantes la aplicación fue revisada por dos expertos a los que se le pidió su opinión sobre los contenidos y la forma en que son abordados. La opinión emitida fue favorable. Se sugirió ampliar las ejercitaciones propuestas a los estudiantes y el glosario de términos, las que fueron tomadas en consideración por el grupo de trabajo. 
Esta aplicación también ha sido utilizada en tres cursos de postgrado para realizar prácticas sobre los aspectos de diseño y confección de guión multimedia, así como los criterios que se utilizan para la evaluación de los productos multimedia. En el curso de postgrado que se impartió en el primer semestre de 1998-99, a graduados de los programas a distancia en la Carrera de Historia, "Multimedios e Historia", donde participaron diez licenciados, se aplicó una planilla de evaluación con cinco bloques de aspectos fundamentales (tiempo de ejecución, orientación que el programa brinda al usuario, elementos de instrucción utilizados, calificación del uso de la música, la animación, gráficos, color, etc., facilidades de composición de textos, impresión, etc.) y calificación cualitativa general que sirvió, no sólo para la ejercitación del curso, sino para recoger sugerencias y opiniones sobre la aplicación.

Se utilizaron items para ser evaluados en una escala con valores entre uno y cinco, donde la categoría inferior de calificación se le atribuyó el valor de "baja” (“1”) y la superior, el de "alta” (“5”). Los resultados más significativos son los siguientes:

La flexibilidad de las ayudas recibió la calificación de “5” por el 70\% de los participantes, el resto lo consideró en un escalón más bajo. El diseño de las pantallas fue calificado de “5” por el 60\%, el 30\% lo consideró de valor " 4 " (uno no contestó). El tamaño de las letras el $80 \%$ lo calificó de " 5 ", pero el resto lo calificó de "2". La utilización de las palabras activas fue calificada por el 50\% de "5" y el resto, lo calificó de "4". La comprensión del lenguaje utilizado y la adecuación de los contenidos al programa de la asignatura, recibió la calificación de “5” por el 100\%.

Este último resultado es alentador en el sentido de que los participantes son egresados de los programas a distancia y ellos, mejor que nadie, pueden valorar la efectividad de la aplicación multimedia como recurso didáctico en el estudio de estos temas.

Donde más dispersión se encontró fue en la valoración del uso del color, la animación, los gráficos y la música. Los gráficos y la música recibieron la calificación de "5" por el 70\% de los participantes, el otro 30\% lo consideró entre "3" y "4". La animación y el color recibió " 5 ” del 60\% y el $40 \%$ restante se dispersó entre los valores “3” y “4”. La calificación cualitativa general de la aplicación de "Excelente” la marcó el 30\% y de "Muy Buena”, el 70\%.

Se hicieron las siguientes sugerencias para mejorar las versiones posteriores:

- Dotarla con un cuadro cronológico comparativo donde se ubiquen las obras.

- Incluir vídeos sobre la vida y la obra de los autores tratados.

- Aumentar las facilidades de impresión de la información contenida en las pantallas.

En los otros cursos de postgrado, en reuniones con los profesores participantes se recogieron las siguientes sugerencias: simplificar las formulaciones de los objetivos, ampliar el número de detalles a seleccionar cuando se muestran las imágenes, eliminar el uso de las letras en itálica, ampliar los puntos de las letras, ampliar el glosario y dar una visión histórica al analizar cada pintor.

Entre las opiniones recogidas se resalta el trabajo interdisciplinario: Pedagogía, Computación, Apreciación e Historia del Arte, que se presenta en forma de resultado tangible en la aplicación multimedia y se subraya la ventaja de editar un documento electrónico como éste que deja atrás la lentitud de las editoriales (Pereira, 1998).

Los aspectos que se han reiterado para mejorar la aplicación multimedia se vinculan a la ampliación de las facilidades de impresión, mayor número de imágenes — sobre todo en lo referente a la selección de los detalles-, ampliación del glosario y cambios en los tipos de letras utilizados. Aunque no se haya manifestado en todos los grupos que han trabajado con esta aplicación, la sugerencia de incluir vídeos es necesaria tomarla en consideración con el objetivo de enriquecer la próxima versión, que está planteada realizarla dentro de dos años. En el transcurso del primer año de este nueva fase de trabajo, se deberá someterla a una evaluación sumativa cuyos resultados, junto con los criterios expuestos, sirvan para dictar las transformaciones pertinentes. 


\section{EL FUTURO DE LOS MULTIMEDIOS EN LA EDUCACION SUPERIOR A DISTANCIA}

La aplicación de las nuevas tecnologías hará posible la introducción de nuevas formas de interacciones en un espacio virtual que al menos posibilitará:

- La retroalimentación del sistema,

- Las interacciones profesor-estudiante y estudiante-estudiante,

- El trabajo grupal

- El acceso a los recursos de información nacional e internacional.

Al hecho del desarrollo de programas educacionales que no tiene barreras espaciales, ni temporales, se agrega ahora la interactividad entre el '<emisor» del mensaje educativo y el «receptor». Además, por interactividad también se incluye el diálogo entre usuario y un sistema que dispone de informaciones o de recursos (Cartier, 1991), lo que no es posible dentro de los medios unidireccionales, donde el receptor es un agente pasivo, que sólo recibe información.

El diseño instruccional tiene que incorporar las nuevas herramientas didácticas y las nuevas formas de comunicación propiciadas por las nuevas tecnologías. Estas innovaciones no pueden contemplarse dentro de los diseños que consideran la informática como simple herramienta didáctica que se yuxtapone al diseño del curso basado en los materiales escritos y otros medios. Hoy en día existe una verdadera explosión de investigaciones educacionales donde el eje central es el diseño y evaluación de cursos desarrollados mediante las nuevas tecnologías. Cursos completos se implementan e imparten a través de redes locales de aprendizaje o mediante Internet. Aunque en muchos casos se incorporan las experiencias del diseño instruccional para los cursos tradicionales, la propia práctica hace cambiar su fisonomía y aparecen elementos que enriquecen los principios del diseño instruccional.

De lo que se trata es de entender que se han creado nuevas formas de comunicación, nuevas maneras de acceder y producir conocimiento. Comprenderlas en toda su dimensión nos permitirá generar buenas prácticas de la enseñanza para la escuela de hoy. (Litwin 1994).

En estos momentos se está produciendo una fusión entre multimedia y las redes de información, es por ello que será necesario un conocimiento efectivo sobre la forma de diseñar cursos donde intervenga la interactividad de los multimedia combinada con las formas de comunicación posibles mediante las redes de información, también denominadas redes de conocimiento. Pero en muchos casos podemos utilizar los CD-ROM para distribuir nuestras aplicaciones multimedia. Los discos compactos, CD-ROM, son fáciles de manipular y duraderos, los que pueden ponerse a disposición de los estudiantes, bien para ser utilizados en los laboratorios de los centros de educación a distancia o en calidad de préstamo para aquellos estudiantes que posean los medios necesarios como una PC Multimedia en el hogar.

Las experiencias obtenidas en la elaboración y utilización de la aplicación multimedia "Grandes Maestros del Renacimiento" nos han permitido incorporar nuevas ideas y temáticas para confeccionar otros proyectos de trabajo con multimedia. En cierta medida han servido para quebrar la indiferencia y la inercia generada por el desconocimiento del medio, romper con la concepción de que los métodos tradicionales, por ser los conocidos son los más eficaces, se han roto tabúes, se han generado discusiones, se ha desencadenado una oposición fundamentada en lo costoso de la tecnología y la existencia de otras prioridades, se han polarizado los criterios y de esta forma hemos aprendido de una parte y otra, a dominar los conceptos, a conocer lo que es en sí la tecnología de multimedios. Por tanto, el saldo para la institución educativa es positivo. Y gracias a la aceleración de los procesos en este terreno, el tiempo actúa a nuestro favor.

\section{CONCLUSIONES}

En las condiciones en que se desarrolla la educación a distancia en nuestra Facultad, la utilización de los multimedia presenta una inconveniente: nuestros estudiantes tendrían que disponer de tiempo para trasladarse hacia la sede central y asistir a un aula especializada que cuente con los equipos necesarios, a semejanza con el servicio brindado por las bibliotecas. Los estudiantes que vivan en municipios alejados, tanto de Ciudad Habana como de Provincia Habana, estarán en desventaja hasta que se disponga de recursos para la creación de laboratorios en los subcentros de educación a distancia que se crearán en los municipios, no obstante, tendrán la posibilidad del acceso a dicha tecnología. 
Una cuestión importante, que estimamos debe ser considerada en nuestros diseños para multimedia, es la heterogeneidad de los estudiantes a distancia. Esta heterogeneidad imprime características especiales al uso de cualquier recurso didáctico: diferencias en formación, en intereses, en la situación académica, situación laboral, nivel cultural, etc. Es por ello que creemos necesario dar las mayores posibilidades de ajustar la aplicación a estas características individuales. Existe toda una literatura que se ocupa de las investigaciones referidas a los hipertextos adaptativos que deben ser analizada para su posible aplicación. De la aplicación de estas técnicas, los multimedios podrá ser más funcional en los programas a distancia.

En el caso de nuestro entorno de aprendizaje, hemos constatado que nuestros estudiantes trasladan sus hábitos de estudio para al aprendizaje con multimedios. La aplicación multimedia para estudiantes a distancia debe tener en cuenta esta situación y propiciar mecanismos que respeten dichos hábitos y les posibilite los medios para que el conocimiento así adquirido no se "volatilice”.

La introducción de estas tecnologías incluye analizar los cambios que deberán producirse paulatinamente en las propias instituciones, así como en el curriculum. Este último aspecto se basa también en determinados resultados obtenidos de la experiencia, que indican que la aplicación de estas tecnologías deben insertarse en la vida real de la institución y no considerarlas como algo aislado.

Los actores para la apropiación de las nuevas tecnologías dentro de la institución educativa son fundamentalmente los profesores-tutores y estudiantes. En estos momentos se está produciendo una fusión entre multimedia y las redes de información, lo que sitúa, en primer lugar, el conocimiento que los profesores deben poseer sobre la forma de diseñar cursos donde intervenga la interactividad de los multimedios combinada con las formas de comunicación que hacen posibles estas redes. Estos estilos nuevos requieren nuevas habilidades de lectura y escritura para vincular la variedad de medios visuales, de comunicación escrita y verbal, así como la utilización de los mensajes interactivos. El desplazamiento de un modelo de educación a distancia basado en materiales escritos y caracterizado por la poca interactividad hacia un modelo interactivo requiere que dichas habilidades se desarrollen tanto en los profesores y diseñadores de cursos, como en los estudiantes.

Ahora bien, la incorporación de la tecnología por si misma no es suficiente para fomentar y sostener cambios verdaderamente significativos en las instituciones educacionales. El aprendizaje del uso racional y efectivo de la tecnología es difícil y también lo es fomentar las transformaciones organizacionales, ambos requieren la intervención activa del hombre. Estas innovaciones o experiencias referentes a la introducción de las nuevas tecnologías se producen en un contexto específico y sobre ellas actúan una multitud de condicionales, no solamente de consideraciones financieras, sino también de las actitudes, las preferencias y el sistema de valores y creencias de los colectivos humanos. Estas condicionales marcarán sin duda la trayectoria que emprenderemos, pero el problema esencial es la velocidad de difusión de las nuevas tecnologías de información y comunicación, que se introducen en toda la vida social. Lo podremos comprender antes o después, es mejor que sea lo antes posible; de esta forma potenciaremos nuestra inteligencia en su aprovechamiento a favor de nuestros objetivos educacionales.

\section{REFERENCIAS BIBLIOGRÁFICAS}

AZARMSA, R. (1996) Multimedia: Interactive video production. Wadsworth Publishing.

DoRAnDo, S.(1992) Qué son los multimedia? RED-Revista de Educación a Distancia, No.4, junio, pp. 27- 34, Madrid.

ENSWISTLE, N. (1988) La comprensión del aprendizaje ene! aula. Paidos, Barcelona.

HAa.sIM, L.,( 1995) HELTZ, S., TELEs,L., TuRorF,M. Learning Networks.A Field Guide to Teaching and Learning Online. MIT Press, cambndge, Massachusetts.

LrrwIN, E.(1994) Las Nuevas Tecnologías en los viejos y siempre vigentes debates. Revista Tecnología y Comunicación Educativa, Año \#9, No.23, pp. 41-53, Abril-Junio. México.

MARSHALL, D. y HURLEY, S. (1996) The Design, Development and Evaluation of Hypermedia Courseware for the World Wide Web. Multimedia Tools and Aplication. 3, pp 5-31. Kluwer Academic Publisher, Boston. 
NIPPER, S. (1989) Third Generation Distance Learning and Computer Con ferencin. In Mindwave. Communication Computed and Distance Education, London.

NOA, L., ORDAZ, G. y LEDESMA, L. (1998). Multimedia y Educación a Distancia. Resultados parciales de una investigación. Ponencia presentada en Inforedu'98, en el marco del evento internacional INFORMATICA'98, celebrado en La Habana (febrero).

PEREIRA, M. DE LOS A. (1998) Documento interno presentado de evaluación sobre la aplicación multimedia “Grandes Maestros del Renacimiento”, Facultad de Artes y Letras.

RADA, Roe (1995) Interactive Media. Springer-Verlag, New York.

SPIR0, J.R Y JIHN-CHANG JEHNG (1990) Cognitive Flexibility and Hypertext. Theory and Technology for the nonlinear and multidimensioned tranversal of complex subject matter. En Cognition, Education and Multimedia: Exploring Ideas in High Technology. Lawrence Erlbaum Associates Publisher, London.

\title{
PERFIL ACADÉMICO Y PROFESIONAL DE LA AUTORA
}

Luisa A. Noa Silverio. Es profesora Titular de la Facultad de Educación a Distancia de la Universidad de La Habana, Doctora en Ciencias de la Educación Superior y Responsable del Grupo de Tecnología Educativa de dicha Facultad. Investiga, desde hace algunos años, en la incorporación de forma experimental, de la tecnología multimedia a los programas a distancia.

\author{
Dirección: \\ Facultad de Educación a Distancia \\ Universidad de La Habana \\ Edificio Varona \\ San Lázaro y Calle L \\ Vedado. CP 10400 \\ Hab. 4. Cuba. \\ Teléfono: (537) 781112 \\ FAX: (537) 335773 \\ e-mail: luisanoa@fed.uh.cu
}

